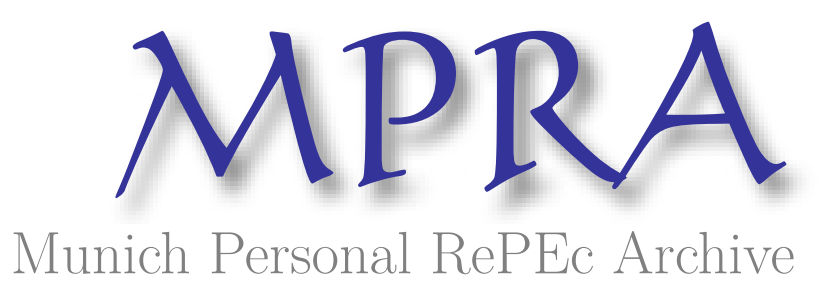

\title{
On the Value of Participation: Endogenous Emergence of Social Norms in a Three-Player Ultimatum Game
}

Grimalda, Gianluca and Kar, Anirban and Proto, Eugenio

Warwick University

27 December 2006

Online at https://mpra.ub.uni-muenchen.de/1620/

MPRA Paper No. 1620, posted 02 Feb 2007 UTC 
On the Value of Participation:

Endogenous Emergence of Social Norms in a Three-Player Ultimatum Game Experiment

\author{
Gianluca Grimalda* \\ Anirban $\mathrm{Kar}^{* *}$ \\ Eugenio Proto $^{* *}$
}

\begin{abstract}
We report results from two different settings of a 3-player ultimatum game. Under the monocratic rule, a player is randomly selected to make an offer to two receivers. Under the democratic rule, all three players make a proposal, and one proposal is then extracted. A majority vote is required to implement the proposal. Although the two rules are strategically equivalent, different patterns of behaviour seem to emerge as the number of interactions increase. Under the monocratic rule proposers seem to be entitled to claim a larger share of the pie, and receivers more likely to accept, in comparison with the democratic rule. We speculate that 'institutions' allowing more participation in the process of collective choice lead to more 'socially responsible' behaviour in the players.
\end{abstract}

Keywords: Majority ultimatum, participation, institutions. JEL classification: C92, C78, D72

Acknowledgments: We thank participants to a seminar at Warwick University for helpful feedback. We also thank Patricio Dalton, Matthew Rablen and Isabella Sulis for assisting during the experiments. We are grateful to the Warwick University Economics Department for funding this research.

\footnotetext{
* Centre for the Study of Globalisation and Regionalisation, Warwick University

** Economics Department, Warwick University

Correspondence address: g.f.grimalda@warwick.ac.uk
} 


\section{Introduction}

The question of the formation of institutions and of their evolution over time has received growing attention within the social sciences. The works of Douglass North (1990) and Amartya Sen (1999) have been notable attempts to approach the subject from an inter-disciplinary perspective, where 'economic' and 'political' factors of analysis interact with one another. In its focus on the relationship between governance and economic development, the recent book by Acemoglu and Robinson (2006) is one of the most remarkable achievements of this newly-developing approach.

However, this strand of literature, which may be grouped under the heading of 'New Political Economy' (Besely, 2004), still seems to suffer from its almost exclusive reliance on the homo-economicus paradigm, i.e. the idea that individual behaviour is largely accountable by the rational pursuit of one's own self-interest. This approach is still widely utilised in economics, in spite of the growing evidence coming from the experimental literature that additional motivations need to be taken into account to provide a satisfactory explanation of human behaviour (Camerer, 2003; Henrich et al., 2004). In fact, economists still struggle to explain the process of full political enfranchisement and the massive participation in the voting process with a purely selfinterested model of individual behaviour. On the other hand, the experimental literature has typically focused on complex institutional settings, such as committee decisionmaking, electoral competition among candidates, and on the relationship between information aggregation and committees (see e.g. Schram and Sonnemans, 1996; Tyran, 2004; and Palfrey, 2005, for a survey). Perhaps paradoxically, what seems to be lacking in this literature is an understanding of the basic individual motivations with respect to institutional settings.

The purpose of this paper is to increase our understanding of individual motivations in relation to institutional settings using an experimental approach ${ }^{1}$. Our focus is on a basic aspect of democratic institutions, that is, the participation in problems of collective choice. We observe individuals' behaviour in two different institutional settings, one allowing individuals more participation in a bargaining problem than the other. Apart from this feature, the two institutional settings are identical. In particular, the two settings are strategically equivalent from the game-theoretic point of view, i.e. rational payoff-maximising agents should behave in precisely the same manner in the two contexts. Every difference that emerges may thus be attributed to the value that individuals attach to the different degree of participation in the collective problem ${ }^{2}$. We are particularly interested in studying whether the manipulation over the amount of participation in bargaining leads to significantly different outcomes in terms of efficiency and payoff inequality. We also elicit individuals' preferences over the institutional settings, and study their determinants.

The situation of interaction is an extension of the Ultimatum Game (UG) (for a review, see Camerer, 2003: Chapter 2) to three players. In the basic UG, an individual the proposer - makes a proposal to another individual - the receiver - on how to divide a pie. The receiver then has the option of either accepting or rejecting the proposal. If she rejects, then the proposal is not implemented and both receive a payoff of 0 . If she accepts, then the proposal is implemented, and the participants receive the share of the

\footnotetext{
${ }^{1}$ For an overview of the underpinnings of the experimental approach, see Kagel and Roth (1995), and Camerer (2003).

${ }^{2}$ Bolton et al. (2000) adopt the same approach of comparing the outcomes of strategy-equivalent interactions in two-player UGs. Their focus is on individuals' perception of procedural fairness, rather than participation in collective choice problems.
} 
pie determined by the proposal. The game theoretic analysis of this interaction is that people should play the only Nash equilibrium of this game, which is given by the proposer claiming the whole of the pie (or the maximum amount compatible with the receivers being better off in accepting the offer rather than rejecting it), and the receiver accepting this offer. Experimental behaviour is instead markedly different. Several offers with positive amounts are rejected by receivers, and proposers seem to discount that by claiming only a part of the pie for themselves. In fact, the modal offer is in most experiments the equal split of the pie.

Although the literature on two-player UGs has now reached mammoth proportions, UGs involving more than two players are not so common. Exceptions are those studies testing the Baron and Ferejohn (1989) model of dynamic multi-player bargaining. So, Frechette et al. (2003), Diermeier and Morton (2003) and Hsu et al. (2004) conducted experiments on 5-player and 3-player UGs with the main objective of testing the patterns of coalition formation in a context of repeated bargaining. In particular, at each stage of the interaction a proposer is drawn at random within a pool of players and makes an offer to any of the remaining players. A majority rule is then required to implement the proposals. Given the possibility for a proposer to specify different allocations for the receivers, coalitions are likely to be formed, in which a minority of players is systematically excluded from the sharing of the pie from a majority.

Another strand of literature using multi-player UGs is that interested in studying individuals' preferences for fairness and inequity aversion. For instance, strategic considerations are pitted against concerns for fairness in Guth et al. (1996) and Guth and van Damme (1998). In the former study three players play a pair of concatenated twoplayer UGs, with a player acting as receiver in the first UG and as proposer in the second. In the latter a third inactive player is a recipient of the allocation of the pie between a proposer and a receiver. Knez and Camerer (1995) investigate the interaction in which a proposer makes two simultaneous offers to two receivers having positive and possibly different outside options. This is done to test if social comparisons between the two receivers significantly alter their behaviour. Finally, Kagel and Wolfe (2001) test existing theories of inequality aversion in a study in which a proposal implies an allocation for two receivers, one of whom is chosen at random to either accept of reject the proposal.

In the present paper we are not interested in either coalition formation or preferences over distribution, so we make some relevant changes to the settings described above. More precisely, the proposal's offer is equally divided between the two receivers, so that there is no possibility for the proposer to form a coalition with one of the two receivers, and receivers are not influenced by the relative payoff with respect to the other receiver. Moreover, similarly to Baron and Ferejohn (1998), both receivers are called to vote over the proposal. If both of them reject the proposal then everyone obtains a payoff of 0 , otherwise the proposal is implemented and the participants receive their share according to the proposal.

Perhaps more importantly, the main goal of our experiment is to compare two different kinds of 'rules' under which the above interaction is played. In the 'monocratic' rule, a proposer is randomly selected $e x$ ante, and she becomes the only person to propose a division of the pie. In the 'democratic' rule, all of the three group members, individually and simultaneously, make a proposal. One proposal among the three is then selected by a random draw, and the receivers decide whether to accept or reject. Even in this case, two rejections are necessary for the proposal not to be implemented.

The thrust of our experiment is thus that the two rules are 'strategy equivalent', in the sense that the expected payoffs are ceteris paribus the same under the two rules. However, they offer different degrees of participation to the subjects in that everyone 
gets the opportunity to put forward a proposal in the democratic rule, whereas only one participant is entitled to do so in the monocratic rule. Moreover, the fact that all players are asked to submit a proposal in the democratic rule creates a 'veil of ignorance' that may force agents to reflect on the possibility of 'role reversal' and act accordingly'. It is thus plausible that an agent takes into account the division she herself proposed (but was not chosen in the random draw), while responding to the selected offer.

The results of the experiments point to the emergence of different patterns of behaviour in the two rules. In the monocratic rule proposers seem entitled to demand a larger share of the pie, and receivers seem to be more lenient in accepting low offers than in the democratic rule. Therefore, one may conjecture that institutional settings allowing more participation bring about more equality in payoff distribution, but also more conflict, as individuals are less prone to accept unequal offers from the proposer. More generally, this result highlights that even strategy-irrelevant differences in the institutional settings may lead to substantially different outcomes. These patterns do not occur immediately, but emerge as the number of interactions increase. On the one hand, this suggests that social interaction is necessary for such patterns to emerge, rather than being unconditional 'hard-wired' individual propensities. But this also points to the necessity of interpreting these results with caution, as a larger number of interactions than the one employed in this study may be necessary to test the asymptotic robustness of the patterns of behaviour.

The paper is organised as follows. Section 2 illustrates the protocol of the experiment. Section 3 outlines the results. Section 4 concludes.

\section{Experimental Protocol}

Non-cooperative games have three basic components - players, rules and information available to the players. We shall describe our experiment by looking at these features one by one.

Rules: There are two sets of separate rules under which a three-player group can play the game.

Monocratic Rule: A group of three is formed. One of the players is chosen randomly (with equal probability) to act as a 'proposer' of an UG. First, the 'proposer' proposes a division of a pre-announced sum of money $(\mathrm{X})$. A proposal consists of a single number, say $\mathrm{Y}$, less than or equal to $\mathrm{X}$ that the 'proposer' wants to keep for herself. The residual amount is shared equally between the two remaining players (called 'receivers').i.e. it amounts to [(X-Y)/2]. After the proposal has been made, the receivers obtain the information as to their share. They are then asked either to 'accept' or 'reject' this proposal individually. If both of them choose to 'reject' the proposal, then the proposal is not implemented and all the players of the group receive 0 . For all other possible responses the proposal is implemented, that is the 'proposer' receives $\mathrm{Y}$ and the 'receivers' obtain $(\mathrm{X}-\mathrm{Y}) / 2$ each.

Democratic Rule: Like the monocratic rule, a group of three is formed before the start of the game. Firstly, all the three players are asked to submit a proposal of division of X (same amount as in the previous rule). Again, a proposal consists of an amount $Y$ that a player wants to keep for herself. The residual amount is divided equally $[(\mathrm{X}-\mathrm{Y}) / 2]$ between the remaining two players. Once all of the three proposals have been submitted, one of them is chosen randomly (with equal probability). The chosen proposal then goes to all the players indicating their own share. Players can either choose to 'accept' or 'reject' this proposal

3 In a different context, Bolton (1991) suggested this possibility. 
individually. If a proposal is 'rejected' by majority voting (at least 2 rejections out of 3 ) then all the players receive 0 each. Otherwise the proposal is implemented, that is, each player is paid according to the proposal ${ }^{4}$.

The game-trees for the two rules are reported in Figures 1 and $2^{5}$. It should be clear that the main difference between the two rules lies in the point where Nature plays. In the monocratic rule Nature plays first and draws at random the proposer. In the democratic rule, players are all allowed to make a proposal, and then Nature selects one among the three proposals.

Players: The experiment has been conducted on a population of 47 Warwick University students. Subjects were recruited in four different sessions, involving 12 subjects for the first three sessions and 11 for the last. Each session was organised according to the following protocol: Subjects played a block of 3 rounds under a rule, then a block of 3 rounds under the alternative rule. After the $6^{\text {th }}$ round they were then asked to choose which rule they would have preferred to play in the last block of 3 rounds, knowing that they would have played under the rule they chose in the last block ${ }^{6}$. Since we conjectured that order effects in the presentation of the two rules may affect subjects' behaviour, we counterbalanced the order in which subjects played the two rules.

In summary, the timing of decisions was as follows:

- $1^{\text {st }}$ Block: Individuals play rule i for 3 rounds

- $2^{\text {nd }}$ Block: Individuals play rule j for 3 rounds

- Choice of the rule

- $3^{\text {rd }}$ Block: Individuals play the rule they chose for 3 rounds

Information on the Game: Players had full information about the rules of the game. Interactions were entirely anonymous, and groups were randomly redrawn before each interaction. This was done in order to prevent repeated game effects to occur, such as reputation and reciprocity effects. At the end of each interaction players were told whether the proposal had been implemented or not, along with their own payoff, from which they could also infer that of the other two players. However, subjects were only paid for three rounds in total, each of which was randomly drawn at the end of the experiment from each of the three blocks. In this way, subjects learned from experience. No communication was allowed among players at any time during the session. Subjects' comprehension was tested through some quizzes after the instructions had been delivered. No subject failed a quiz.

\footnotetext{
${ }^{4}$ The main reason why proposers were also asked to vote on their own proposal was to enhance the democratic character of the procedure, because a proper majority voting was necessary in order to reject a proposal. Although this creates a slight procedural difference in comparison with the monocratic rule, we do not believe the results would change if the extracted proposers were excluded from the vote, as in the monocratic rule. In fact, not surprisingly, all proposers voted in favour of their own proposal in the experiments.

${ }^{5}$ For simplicity, the branch of the tree departing from the proposer rejecting her own proposal has not been reported in Figure 2. As mentioned in the previous footnote, all the proposers accepted their own proposals.

${ }^{6}$ When the subjects' choice was not consistent with making up groups of 3, three extra players were involved for the last block of interactions only.
} 
Figure 1

Game-Tree for the Monocratic Rule

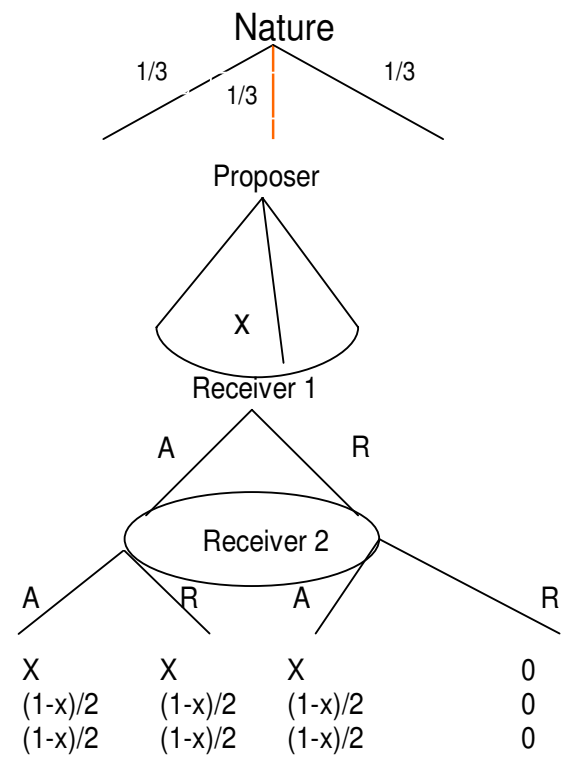

Figure 2:

Game-Tree for Democratic Rule

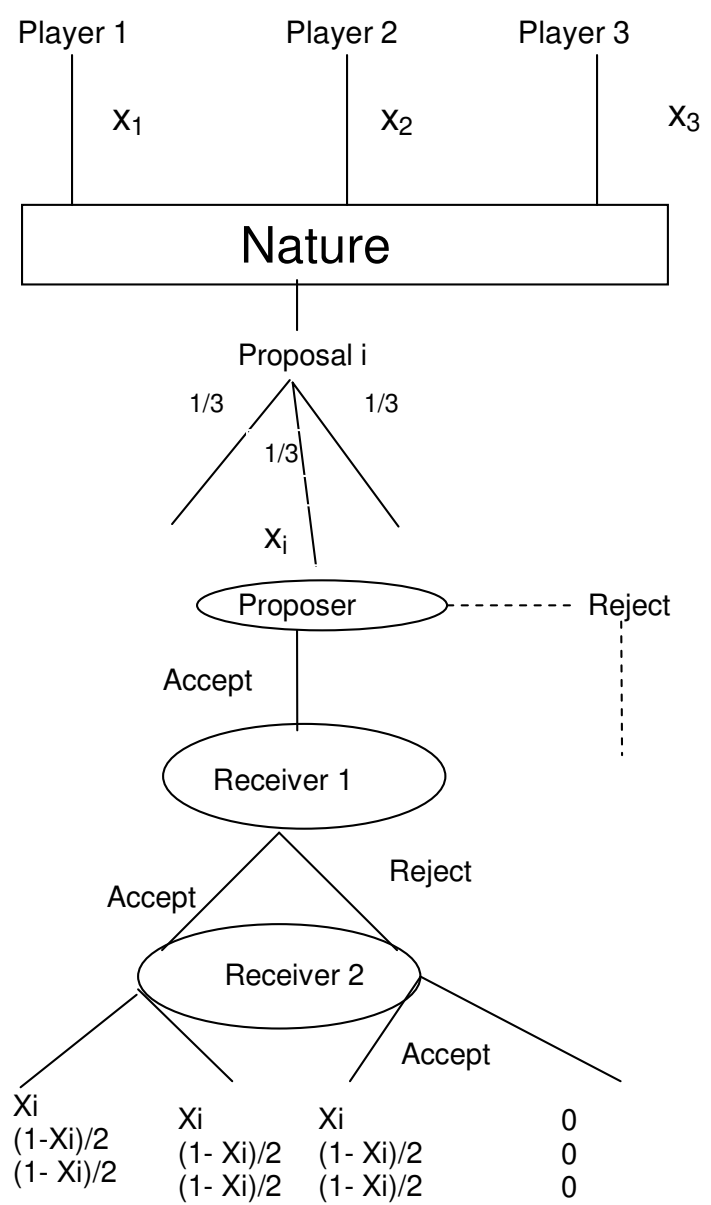




\section{Results}

\subsection{Overview}

Figure 3 plots the distribution of proposals for all of the observations in our experiments. Note that by proposal we mean the share of the pie that the proposer demands for herself. We instead call an offer the allocation accruing to each individual receiver in relation to a certain proposal. In two-player UGs the mode of the proposals is generally the 50-50 split, whereas the average proposal is in the region of $60-65 \%$ of the pie (see e.g. Guth et al., 1982; Knex and Camerer, 1995). One would perhaps expect that in our three-player game the presence of two receivers would lead the proposer to demand less for herself and propose an equitable distribution of the pie among all of the three players. Figure 3 shows that this is not the case. Only around 5\% of the proposals demand less than $40 \%$ of the pie. Moreover, the mode of the distribution is $60 \%$, which is even higher than the mode for twoplayer UGs. The mean of the proposal is instead in line with two-player UGs, being equal to 6.19 (see Table 1). Therefore, proposers seem to be little concerned with the overall inequality among the group, but appear to be entitled to a share of the pie as large as that normally claimed by a proposer facing only one respondent. Broadly speaking, this is consistent with Guth and van Damme (1998), who find even higher demand rates for proposers in their three-player UG design. The substantial differences in their design however prevent the full comparability of our results.

The comparison of the histograms of proposals under each rule (Figure 4) reveals that the mode of proposals is $80 \%$ under the monocratic rule, and $60 \%$ under the democratic one. The impression that the distribution of proposals under the monocratic rule is more skewed towards the right than the democratic rule is confirmed by the fact that the former has a higher mean (6.32) than the latter (6.15) (see Table 1). Note that the number of observations for the democratic rule is higher because proposals have been included in the count even if they were not extracted for public vote.

Figure 3

Histogram of Proposals (Total)




Figure 4

Histograms of proposals for each rule

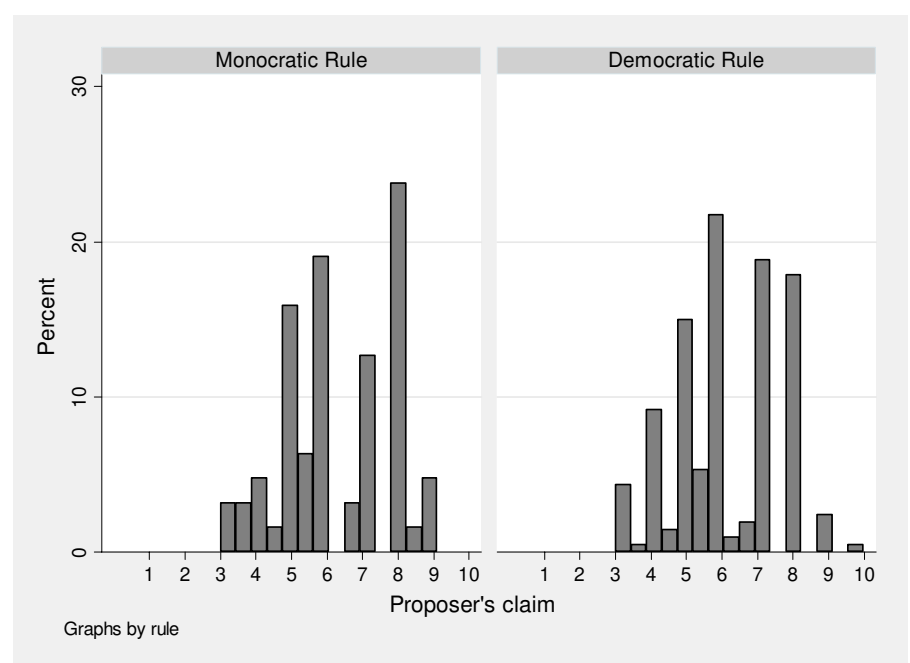

Table 1

Summary Statistics for Proposals (Total and for each rule)

\begin{tabular}{lccccr}
\hline Variable & Observations & Mean & Std. Dev. & Min & Max \\
\hline $\begin{array}{l}\text { Proposal } \\
\text { (Total) }\end{array}$ & 270 & 6.19 & 1.47 & 3 & 9.98 \\
\hline $\begin{array}{l}\text { Proposal } \\
\text { (Monocratic }\end{array}$ & 63 & 6.32 & 1.55 & 3.33 & 9 \\
Rule) & & & & & \\
\hline $\begin{array}{l}\text { Proposal } \\
\begin{array}{l}\text { Democratic } \\
\text { Rule) }\end{array}\end{array}$ & 207 & 6.15 & 1.45 & 3 & 9.98 \\
\hline
\end{tabular}

The overall results relative to the receivers' acceptance rates of proposals are reported in Table 2. $a$ represents the offer implied by the proposal they received. Table 2 reports the frequency with which individual receivers responded they would accept an offer in a certain range, regardless of whether the proposal was in fact implemented. That is, we consider individual acceptances rather than group acceptance rates (remember that two rejections were necessary to reject the offer). Moreover, we take out of the count proposers' own responses in the democratic rule, as this would obviously bias upwards the acceptance rates (see footnote 4).

Looking at the total acceptance rates (first row of Table 2), one can note that the acceptance rates is $72 \%$ in both rules. Given that the mean proposal is higher in the monocratic than in the democratic rule (see Table 1), this suggests that receivers are ceteris paribus more inclined to accept proposals under the monocratic rule. Table 2 reveals that this is certainly the case for each of the four categories below $20 \%$ of the pie. In particular, receivers in the monocratic rule accepted 2 out of 8 offers below $10 \%$ of the pie, whereas receivers in the democratic rule accepted none of their 10 proposals in the same category. On the other hand, acceptance rates are higher in the democratic rule for offers between $20 \%$ and $30 \%$. This pattern is reversed in the last category of offers equal or above $30 \%$, where all offers are accepted in the monocratic rule, whereas one offer out of 14 is rejected in the democratic rule. 
Table 2

Acceptance Rates (Total and for each Rule)

\begin{tabular}{lrrrrrr}
\hline Allocation & \multicolumn{2}{c}{ All } & Monocratic Rule & Democratic Rule \\
\hline & $\mathrm{N}$ & $\begin{array}{r}\text { Receivers' } \\
\text { Acceptance } \\
\text { Rate }\end{array}$ & $\mathrm{N}$ & $\begin{array}{r}\text { Receivers' } \\
\text { Acceptance } \\
\text { Rate }\end{array}$ & $\mathrm{N}$ & $\begin{array}{r}\text { Receivers' } \\
\text { Acceptance } \\
\text { Rate }\end{array}$ \\
\hline All $a$ & 267 & .72 & 130 & .72 & 137 & .72 \\
\hline$a<0.5$ & 2 & 0 & 0 & - & 2 & 0 \\
\hline $0.5 \leq a<1$ & 16 & .125 & 8 & .25 & 8 & 0 \\
\hline $1 \leq a<1.5$ & 53 & .53 & 29 & .59 & 24 & .46 \\
\hline $1.5 \leq a<2$ & 33 & .55 & 22 & .59 & 11 & .45 \\
\hline $2 \leq a<2.5$ & 77 & .81 & 31 & .77 & 46 & .83 \\
\hline $2.5 \leq a<3$ & 58 & .95 & 26 & .92 & 32 & .97 \\
\hline $3 \leq a$ & 28 & .96 & 14 & 1 & 14 & .93 \\
\hline
\end{tabular}

A Mann-Whitney test on the equality of acceptance rates for offers below $20 \%$ confirms that receivers' behaviour is significantly different across the two rules, though only weakly ( $p$-value $=0.06$; Table 3 , column 1 ). In the test, acceptance is the dichotomous variable that takes a value equal to 1 if an offer is accepted and 0 if rejected. However this result does not hold if allocations equal to $20 \%$ are included in the count. The same test for offers above $20 \%$ does not signal any significant difference in receivers' behaviour across the two rules. Finally, not surprisingly the average value of rejected offers is higher in the monocratic rule than in the democratic rule (Table 4), although the difference is not statistically significant in a Mann-Whitney test.

Table 3

Results of Mann-Whitney tests for the null hypothesis $\mathbf{H}_{0}=($ acceptance $\mid$ monocratic rule $)=($ acceptance $\mid$ democratic rule $)$

\begin{tabular}{lccc}
\hline & $\begin{array}{c}\text { All rounds - } \\
\text { Offer }<\mathbf{2 0} \%\end{array}$ & $\begin{array}{c}\text { Last 3 Rounds } \\
\text { Offer }<\mathbf{2 0} \%\end{array}$ & $\begin{array}{c}\text { Last 3 } \\
\text { Rounds } \\
\text { Offer } \leq \mathbf{1 0} \%\end{array}$ \\
\hline $\begin{array}{l}\text { Observations Monocratic } \\
\text { Rule }\end{array}$ & $(1)$ & $(2)$ & $(3)$ \\
\hline $\begin{array}{l}\text { Observations Democratic } \\
\text { Rule }\end{array}$ & 49 & 19 & 15 \\
\hline Total Observations & 104 & 9 & 6 \\
\hline p-value of $\mathrm{H}_{0}$ & 1.884 & 28 & 21 \\
\hline Significance level & 0.0595 & 2.294 & 2.449 \\
\hline
\end{tabular}

Table 4

Summary statistics for rejected offers in total and per each rule

\begin{tabular}{|c|c|c|c|c|c|c|c|c|c|c|c|}
\hline \multicolumn{4}{|c|}{ All } & \multicolumn{4}{|c|}{ Monocratic Rule } & \multicolumn{4}{|c|}{ Democratic Rule } \\
\hline $\mathrm{N}$ & $\begin{array}{c}\text { Mean } \\
\text { (Std. } \\
\text { Dev.) }\end{array}$ & Min & $\operatorname{Max}$ & $\mathrm{N}$ & $\begin{array}{c}\text { Mean } \\
\text { (Std. } \\
\text { Dev.) }\end{array}$ & Min & $\overline{\operatorname{Max}}$ & $\mathrm{N}$ & $\begin{array}{l}\text { Mean } \\
\text { (Std. } \\
\text { Dev.) }\end{array}$ & Min & $\overline{\operatorname{Max}}$ \\
\hline 75 & $\begin{array}{c}1.31 \\
(0.65) \\
\end{array}$ & 0.01 & 3.3 & 36 & $\begin{array}{c}1.38 \\
(0.60) \\
\end{array}$ & 0.5 & 2.75 & 39 & $\begin{array}{c}1.25 \\
(0.70) \\
\end{array}$ & 0.01 & 3.3 \\
\hline
\end{tabular}


Overall, these results seem to pinpoint a higher conflict rate in the democratic rule for low offers, although this is the case only at weak significance levels.

\subsection{Evolution of behaviour}

Figure 5 plots the evolution of the mean claims that proposers made in the two rules. The horizontal axis refers to the level of experience that players had when playing under a certain rule. For instance, level of experience 1 refers to the first interaction in which players played under a certain rule, level of experience 2 to the second, etc. Note that because of the experiment protocol, the first three interactions were played by the participants before making the choice of the rule. This happened in either block 1 or block 2 , depending on the order with which the rules were played. Conversely, level 4, 5 and 6 were all played in the last block, that is, under the rule that subjects chose to play for ${ }^{7}$. The plot suggests the existence of a trend leading to proposers claiming a higher share of the pie under the monocratic rather than the democratic rule, in spite of a slump in monocratic proposers' claims at level 5.

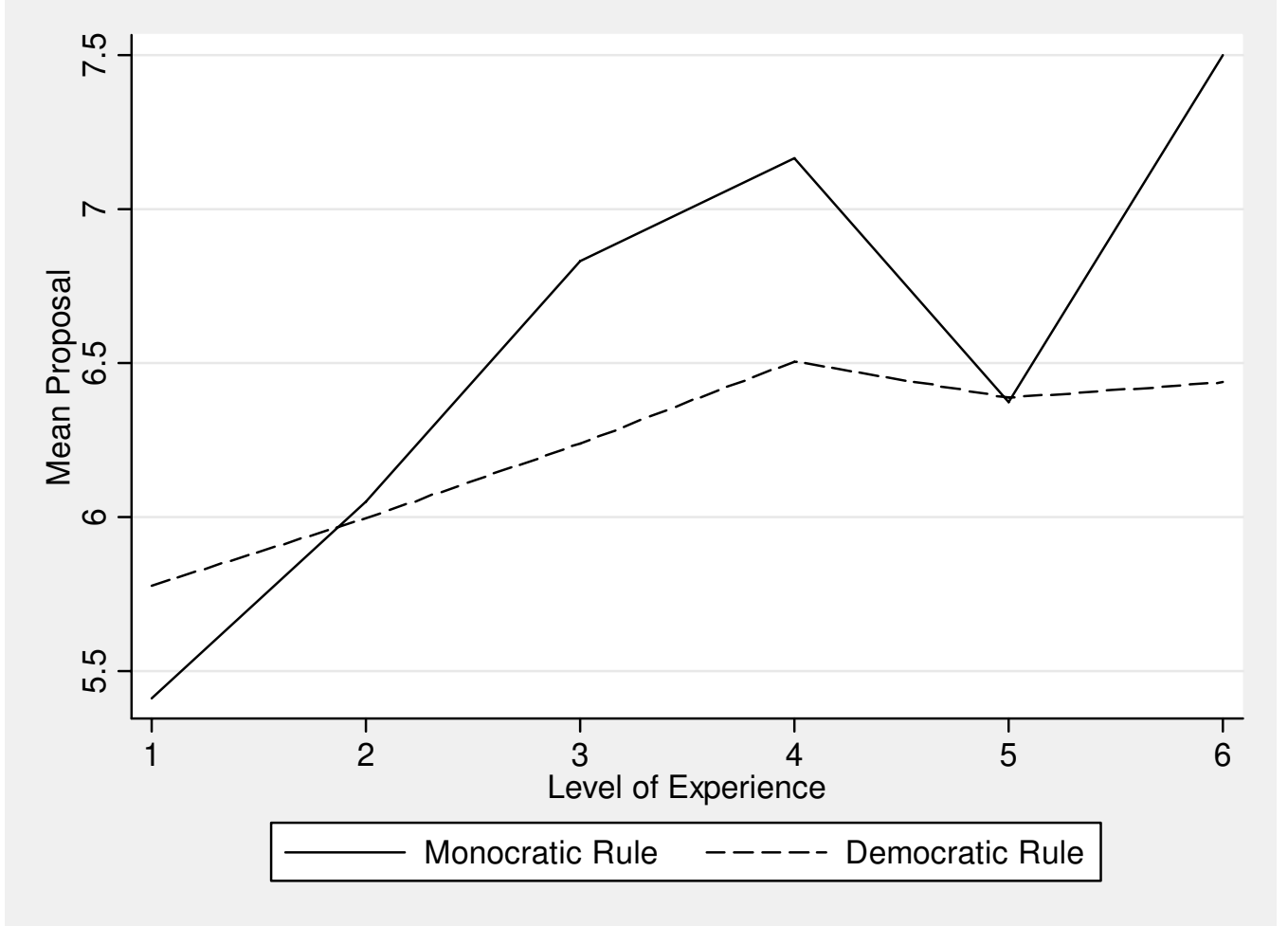

Figure 5

\footnotetext{
${ }^{7}$ Due to a technical problem with the networking connection, we were unable to complete the last two rounds in the last session.
} 
Table 5 shows that the scarcity of observations in the last interactions should make us rather cautious in interpreting these results.

Table 5:

Evolution of Proposal per Rule and per Level of Experience

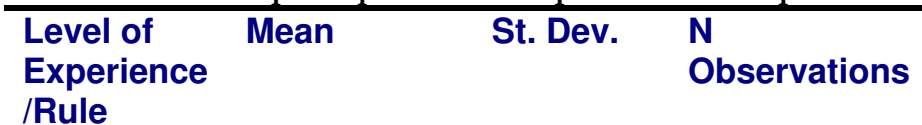

\begin{tabular}{|c|c|c|c|}
\hline \multicolumn{4}{|l|}{ Level 1} \\
\hline Monocratic & 5.41 & 1.50 & 16 \\
\hline Democratic & 5.78 & 1.73 & 47 \\
\hline \multicolumn{4}{|l|}{ Level 2} \\
\hline Monocratic & 6.05 & 1.24 & 16 \\
\hline Democratic & 6.00 & 1.50 & 47 \\
\hline \multicolumn{4}{|l|}{ Level 3} \\
\hline Monocratic & 6.83 & 1.54 & 15 \\
\hline Democratic & 6.24 & 1.25 & 47 \\
\hline \multicolumn{4}{|l|}{ Level 4} \\
\hline Monocratic & 7.17 & 1.06 & 9 \\
\hline Democratic & 6.51 & 1.23 & 24 \\
\hline \multicolumn{4}{|l|}{ Level 5} \\
\hline Monocratic & 6.38 & 2.14 & 4 \\
\hline Democratic & 6.39 & 1.41 & 21 \\
\hline \multicolumn{4}{|l|}{ Level 6} \\
\hline Monocratic & 7.50 & 1.80 & 3 \\
\hline Democratic & 6.44 & 1.23 & 21 \\
\hline
\end{tabular}

Given the paucity of the observations for the monocratic rule, the hypothesis that proposals are the same under the two rules cannot be rejected at a $10 \%$ significance level in the last interaction - as well as in any other interaction. However, if we group interactions together according to some specific levels of experience, the hypothesis that proposals are unequal in the two rules receives some support. In particular, a MannWhitney test weakly rejects this hypothesis at the $8 \%$ level when conducted on the whole of the last three interactions (Table 6, column 1), and by an even larger significance level if the last four interactions are considered (Table 6, column 2). No appreciable difference may be recognised by pooling together all the observations (Table 6, column 3).

Therefore, one may conjecture that after acquiring more experience, proposers think of themselves as being entitled to a larger share of the pie under the monocratic rule vis-àvis the democratic rule.

This result is mirrored by the behaviour of receivers in the two rules. We already showed in section 3.1 that receivers appear to be keener to reject unfair proposals in the democratic rather than in the monocratic rule. This result emerges even more clearly by limiting to the last three interactions. A Mann-Whitney test on the equality of the rejection rates of proposals below $20 \%$ under the two rules is strongly rejected at the $2 \%$ level (Table 3: Column 2). The significance level is even higher by considering rejection 
rates for 'extremely unfair' proposals, i.e. those allocating to the receiver no more than $10 \%$ of the pie (Table 3: Column 3). However, these results relative to rejection rates do not hold if we consider the last 4 rounds level of experience, rather than the last 3.

Table 6

Results of Mann-Whitney tests for the null hypothesis $\mathrm{H}_{0}=($ proposal $\mid$ monocratic rule $)=($ proposal $\mid$ democratic rule $)$

Last 3 Rounds Last 4 Rounds All Rounds

\begin{tabular}{lccc}
\hline & $(1)$ & $(2)$ & $(3)$ \\
\hline $\begin{array}{l}\text { Observations Monocratic } \\
\text { Rule }\end{array}$ & 16 & 31 & 63 \\
\hline $\begin{array}{l}\text { Observations Democratic } \\
\text { Rule }\end{array}$ & 66 & 113 & 207 \\
\hline Total Observations & 82 & 144 & 270 \\
\hline p-value of $\mathrm{H}_{0}$ & 1.747 & 2.098 & 0.782 \\
\hline Significance level & 0.0806 & 0.0359 & 0.4343 \\
\hline
\end{tabular}

Overall, these patterns of behaviour are conducive to a more egalitarian distribution in the 'democratic' rule. As shown by Figure 5, which reports payoffs for receivers provided that the proposal has not been rejected, receivers always get a higher share for all interactions under the democratic rule, and the gap is particularly large in the last three interactions.

Figure 6

Mean Average Payoffs for Receivers in Implemented Proposals

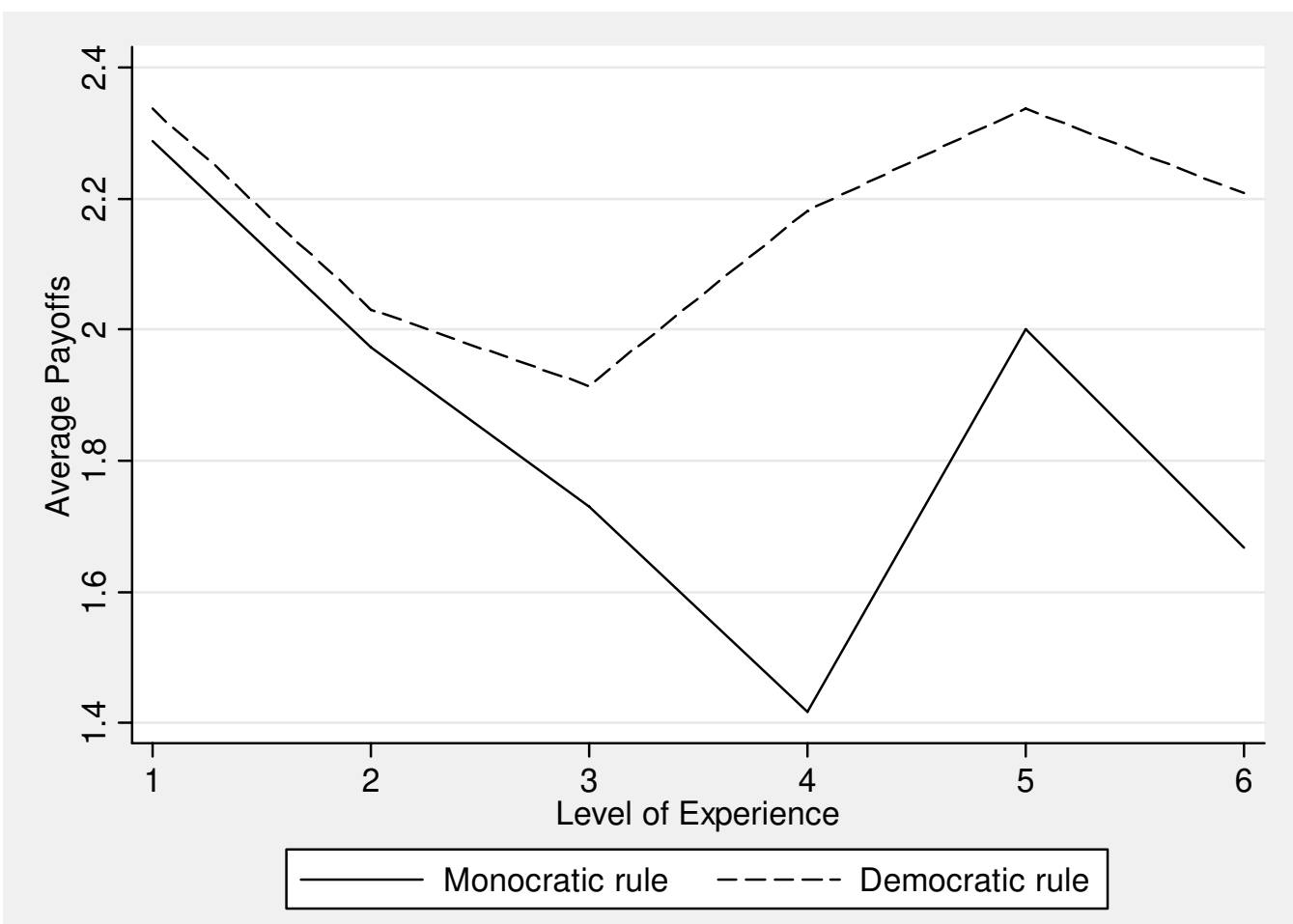




\subsection{Determinants of Rule Choice}

As illustrated in section 2, subjects were asked to play under either rule in the first two blocks of the experiment, and were then asked to express a choice on the rule with which they would play the last block of interactions. Since some of the results presented in the previous section are driven by subjects' behaviour in the last block of interactions, it is interesting to investigate the determinants of subjects' choice.

This reveals that the most important factor appears to be the payoffs earned in the interactions preceding the rule choice. A test on the independence between the payoffs earned under the two rules in the first two blocks, and the rule that has been chosen by subjects, is strongly rejected at less than the $1 \%$ level (Table 7$) \cdot \sum_{r=1}^{3} \pi_{r}(r)$ is the

sum of the payoffs earned in the three interactions played under a certain rule, with $r$ standing for either the monocratic or democratic rule. The test shows that the higher the payoff earned under a certain rule in comparison with the other, the higher the probability of choosing that rule. Moreover, subjects distributed quite evenly in the rule choice, with 25 preferring the 'democratic' rule, against 22 choosing the alternative. Therefore, opportunism seems to be by far the main determinant of people's choice over the two rules.

Table 7:

Results of Mann-Whitney tests for the null hypothesis

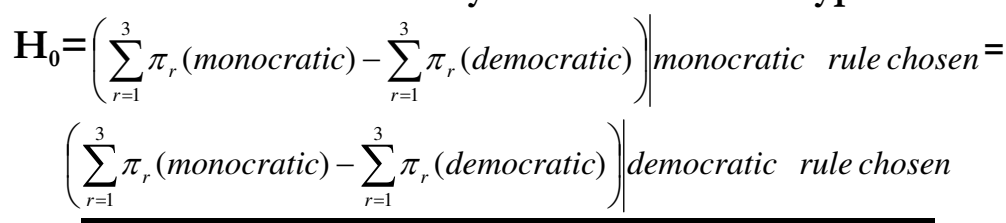

\begin{tabular}{lc}
\hline & Results \\
\hline $\begin{array}{l}\text { Observations Monocratic } \\
\text { Rule }\end{array}$ & 22 \\
\hline $\begin{array}{l}\text { Observations Democratic } \\
\text { Rule }\end{array}$ & 25 \\
\hline Total Observations & 47 \\
\hline p-value of $\mathrm{H}_{0}$ & -3.456 \\
\hline Significance level & 0.0005 \\
\hline
\end{tabular}

\section{Discussion}

On the grounds of this analysis, there seems to be some evidence supporting the idea that the two different institutional settings elicit different patterns of behaviour in the participants in our pilot. In spite of the payoff and strategy-equivalency of the two rules (see section 2), different patterns of aggregate behaviour seem to emerge in the two settings. In particular, proposers are seemingly entitled to demand more, and receivers appear to be inclined to concede more, under the monocratic rather than the democratic rule. Therefore, one may speculate that the rule allowing for a higher participation in collective decision-making initiates a more 'socially responsible' behaviour in all the players, which leads to smaller inequality in the distribution.

However, this conjecture at the same time requires further investigation and raises additional questions. In particular, the process of acquiring experience over a rule that we believe is at the basis of the above result, seems to be entangled with a process of learning over other players' strategies. The presence of the latter effect is best highlighted by 
Figure 7. This plots the mean proposers' claim for each round of the experiment ${ }^{8}$, regardless of which of the rules was played. Had experience over a rule been the only factor affecting the upward trend in the proposals, one would expect that behaviour in round 4 were similar to that in round 1 . This is because all subjects switched the rule under which they were playing after round 3 , and therefore the process of getting experienced under the new rule should restart from zero. However, in round 4 we can only observe a small drop in the mean of the proposals, which only partially offset the upward trend. This is suggestive that learning effects over other players' strategies add to experience effects over a rule. Given the independency of individual decisions, the existence of such learning effects is somehow surprising, in addition to being rather unusual for UGs (see Camerer, 2003: Chapter 2). However, Guth and van Damme (1998) obtain a similar effect.

Figure 7

\section{Evolution of Mean Proposals per Round}

Proposals

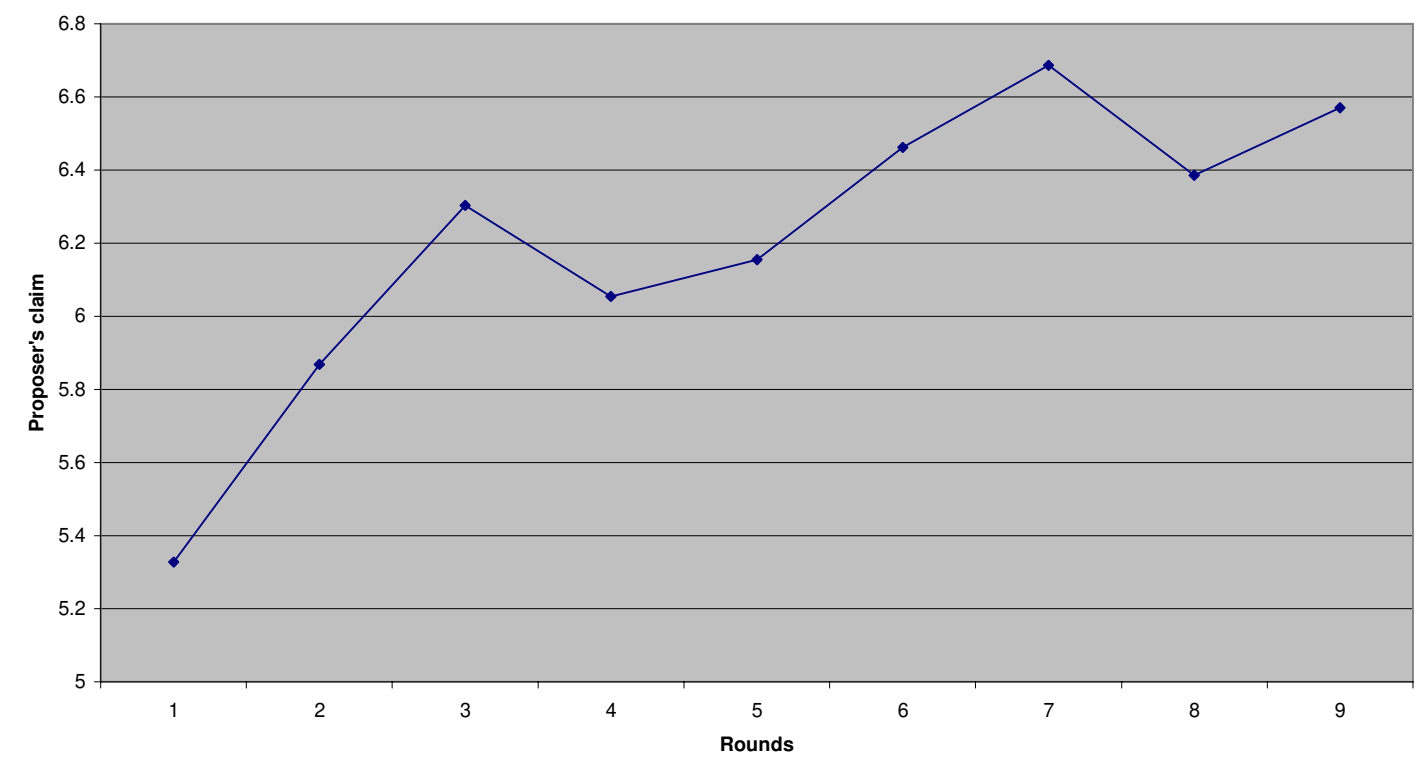

Interestingly enough, such learning effects seems to differ for the two rules. Figure 8 reports the evolution of the mean of the proposals in each round for the two rules. That is, it plots the mean proposal of subjects who played under a certain rule in a certain round. It is apparent that the drop in the mean proposal in round 4 is higher for the monocratic rule. Overall, the average play under the latter shows higher variability than in the democratic one.

\footnotetext{
${ }^{8}$ Therefore, round 1 here refers to the average claims made by all proposers in the first round of the experiment. In particular, this comprises the 8 proposals made by proposers in the monocratic rule, and the 24 made by the would-be proposers in the democratic rule.
} 
Figure 8

Evolution of Mean Proposal per Round and per Rule

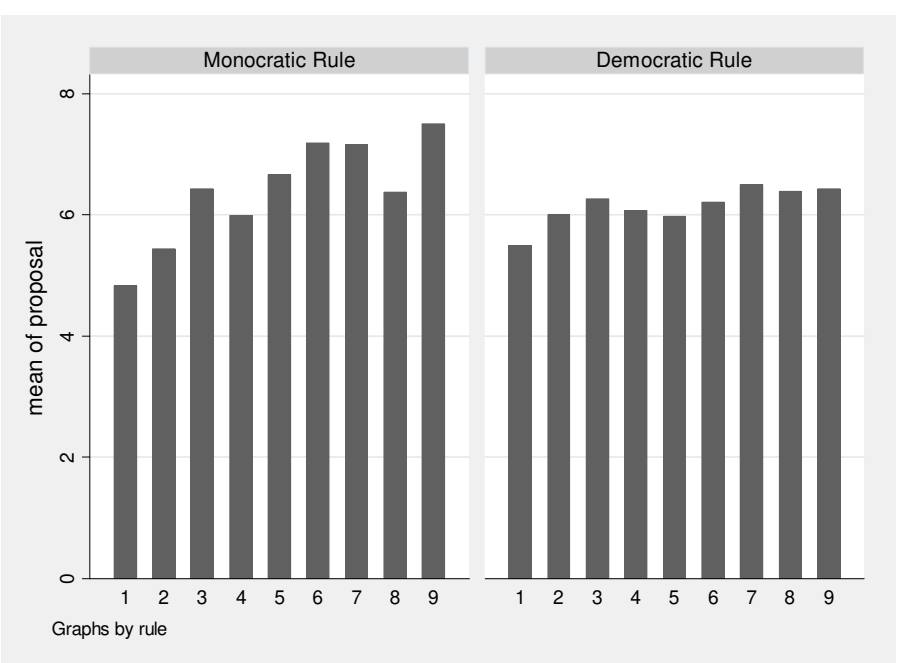

The reason why the learning over others' strategies effect may cause an increase in the proposal rate over time is due to the process of beliefs update over the receivers' 'toughness'. That is, the observation that a certain proposal has not been rejected may lead a proposer to revise upwards her initial beliefs on the minimum offer that is acceptable by a receiver. In other words, a proposer who entered the experiment with certain beliefs on the 'toughness' of her opponents, may realise during the course of the interactions that receivers are more 'soft' than what she initially thought, and this will lead to progressively increase her demand over time. This reasoning is likely to be fallacious because the probability of encountering opponents of the same 'softness' in future interactions is negligible. However, erroneous as it might be, this effect is more likely to manifest in smaller sessions. We thus think that this effect may have been quite strong in our experiment, since sessions included at most 12 subjects. This increases the risk that path-dependence effects and session-specific patterns may have influenced our results, rather than the difference in institutional settings. We therefore plan to check the robustness of these results in future studies by increasing the number of individuals in each session, and also by expanding the number of interactions played.

Moreover, the fact that most of the results seem to emerge in the last block of interactions raises the issue of whether this is due to the end of the learning and experience processes after the first two blocks, or to a self-selection effect. The latter would be the case if individuals modified their behaviour because of the shared choice of a certain rule. The fact that material considerations appear to be determinant in the choice of the rule may detract from the latter idea. However, this aspect seems to be worth further investigation. More generally, the scarcity in the number of observations prevents us from reaching firm conclusions and generalising the results. However, we believe that the present study shows the suitability of the present design to answer the main questions of our inquiry, and that the emerging patterns are worth a more extensive analysis. 


\section{References}

Acemoglu D. and J. Robinson (2006), Economic Origin of Dictatorship and Democracy, 2006, Cambridge University Press.

Baron, D., Ferejohn, D., (1989). Bargaining in legislatures. American Political Science Review, 83, 1181-1206.

Bolton G. (1991), 'A Comparative Model of Bargaining: Theory and Evidence', American Economic Review, Vol. 81.

Bolton, G.E. Brandts, J. and Ockenfels, A. (2000). " Fair Procedures: Evidence from Games Involving Lotteries”, mimeo, forthcoming Economic Journal

Diermeier, D., Morton, R., 2003. Proportionality versus perfectness: experiments in majoritarian bargaining. Mimeo.

Frechette, G.R., Kagel, J.H., Lehrer, S.F., 2003. Bargaining in legislatures: an experimental investigation of open versus closed amendment rules. American Political Science Review, 97, 221-232.

Guth W., R. Schmittberger and B. Schwarz (1982), 'An experimental analysis of ultimatum bargaining', Journal of Economic Behavior and Organization, Vol. 3.

Güth, W., Huch, S., Ockenfels, P., 1996. Two-level ultimatum bargaining with incomplete information: an experimental study. Economic Journal 106, 593-604.

Güth, W., van Damme, E. (1998). Information, strategic behavior, and fairness in ultimátum bargaining: an experimental study. Journal of Mathematical Psychology 42, 227-247.

Henrich, Jospeh, Boyd, Robert, Bowles, Samuel, Camerer, Colin, Fehr, Ernst, Gintis, Herbert (2004). "Fourndations of Human Sociality". Oxford: Oxford University Press

Hsu, Li-Chen, Yang, C.C., Yang, Chun-Lei (2004). Public Good Provision versus Pure Redistribution: An Experimental Study of Majoritarian Ultimatum Games, mimeo

Kagel, J. and A. Roth (1994) The handbook of experimental economics, Princeton university press.

Kagel, J.H., Wolfe, K.W. (2001). Tests of fairness models based on equity considerations in a three-person ultimatum game. Experimental Economics, 4, 203-219.

Knez Marc J. and Camerer Colin F., (1995). "Outside Options and Social Comparison in Three-Player Ultimatum Game Experiments", Games and Economic Behavior, 10, 65-94

North D., C. (1990). Institutions, Institutional Change and Economic Performance, Cambridge University Press.

Palfrey, T. (1995), "Laboratory Experiments in Political Economy", CEPS Working Paper No. 111.

Schram A. and J. Sonnemans (1996), 'Voter Turnout as a Participation Game: An Experimental Investigation', International Journal of Game Theory, Vol. 25.

Sen A. (1999), Development as Freedom, Cambridge University Press

Tyran, J. (2004). "Voting when money and morals conflict: an experimental test of expressive voting", Journal of Public Economics, Vol. 88, 1645-1664 